\title{
Milling Quality Characteristics of Selected Newly Released Rice Varieties of Northern Telangana Region, India
}

\author{
R. Anitha ${ }^{1 *}$, K. Manorama ${ }^{2}$, W. Jessi Sunitha ${ }^{1}$ and M. Sreedhar ${ }^{2}$ \\ ${ }^{1}$ Post Graduate \& Research Centre, Professor Jayashankar Telangana State Agricultural \\ University, Hyderabad, Telangana, India \\ ${ }^{2}$ Quality Control Laboratory, Professor Jayashankar Telangana State Agricultural University, \\ Hyderabad, Telangana, India \\ *Corresponding author
}

\section{A B S T R A C T}

Keywords

Head rice,

Broken rice.

Article Info

Accepted:

26 August 2017

Available Online:

10 September 2017
Brown rice recovery, milled rice recovery and head milled rice recovery are the three essential parameters of milling quality. The selected rice varieties, namely, Anjana (JGL-11118) and Pradhyumna (JGL-17004) were analysed for milling quality characteristics. The head rice and broken rice percentages of selected rice varieties were 37.08 percent and 62.97 percent and 29.76 percent and 70.23 percent respectively. The quality of rice should have head rice out turn of at least 70 percent. Low head rice out turn may be due to chalkiness, varietal characteristics, cultivation practices, harvesting methods and environmental condition and also previous studies reported that milling recovery depends on grain shape and appearance, which has direct effect on the percentage of hulling, milling and head rice recovery.

\section{Introduction}

Rice is a staple food consumed by more than half of the world population (FAOSTAT, 2014). It provides 20 percent of the world's dietary energy supply, while wheat supplies 19 percent and maize (corn) 5 percent (FAO, 2004). It is the predominant dietary energy source for 17 countries in Asia and the Pacific and 9 countries in North and South Africa. In 59 countries, an average of at least $75 \mathrm{~g}$ of rice is available per person per day (FAOSTAT, 2014). The total population of these countries is 4.1 billion which indicates that reaching even half of that population would ensure a greater daily nutrient intake among 2 billion people (FFI, 2014). Rice from which only husk has been removed, but layers of bran and most of the germ retained is known as brown rice.

Rice from which husk germ and bran layers have almost completely been removed by power machinery is known as milled rice. Rice milled to a high degree is known as white rice. Rice milled to a high degree and then coated with some foreign substance such as glucose is called polished rice. Whole 
grains are naturally nutritious foods that have the entire grain intact. It has more fibre, antioxidants such as vitamin $\mathrm{E}$, and trace minerals, compared to more refined grains and have been found to help reduce the risk of heart disease, certain cancers, type II diabetes and potentially aid in weight maintenance (USDA, 2005). With only the inedible hull removed, brown rice is a $100 \%$ whole grain and contains beneficial phytonutrients (Rahman et al., 2006).

Despite numerous studies on different varieties of rice, there is lack of published data on milling quality characteristics of newly released rice varieties of Telangana.

Hence, the present study is undertaken to assess the Milling quality characteristics of the selected newly released rice varieties.

\section{Materials and Methods}

One of the new released rice varieties viz Anjana (JGL-11118) and Pradhyumna (JGL17004) were procured from Regional Agricultural Research Station, Jagityal, Karimnagar.

\section{Experimental design}

Milling quality characteristics like husked rice percentage, head rice percentage, broken rice percentage and milling recovery percentage were analysed using standard procedure (Sahay and Singh, 2005). A minimum hundred grams of paddy were weighed and subjected to dehusking in a standard dehusker/sheller. After cleaning, the dehusked kernels were weighed using an analytical balance.

\section{Statistical analysis}

Mean and standard deviation for three parallel replicates were calculated. Analysis of variance (ANOVA) was used to test the difference between means (Snedcor and Cochran, 1983)

\section{Results and Discussion}

Milling quality characteristics of rice varieties were assessed using "Dehusker (Rice shellerIndosaw), analytical balance and rice grader". The selected rice varieties namely Anjana (JGL-11118) and Pradhyumna (JGL-17004) were analysed for milling quality characteristics and the results are presented in Table 1.1. The Brown rice and husk percentage of Anjana (JGL-11118) and Pradhyumna (JGL-17004) rice varieties was 76.48 percent and 25 percent and 70.76 percent and 27 percent respectively. Cruz and Khush, (2000) reported that brown rice percentage varied from 77-80 percent while the percentage of husk varied between 20- 23 percent which was within the range acceptable for commercial production. Generally husk contributes 20-22 percent of rough rice, although variation of 18-26 percent has been recorded.

The head rice and broken rice percentages of Anjana (JGL-11118) and Pradhyumna (JGL17004) rice varieties were 62.97 percent, 37.08 percent and 70.23 percent, 29.76 percent respectively.

Table.1 Variation of milling quality parameters of two newly released rice varieties in Northern

\section{Telangana region}

\begin{tabular}{|l|l|l|l|l|l|l|}
\hline Variety Name & Accession No & Brown rice\% & Husk rice\% & Total milled rice\% & Head rice \% & Broken rice\% \\
\hline Anjana & JGL-11118 & 76.48 & 25.0 & 62.03 & 62.97 & 37.08 \\
\hline Pradhyumna & JGL-17004 & 73.24 & 26.74 & 58.83 & 70.23 & 29.76 \\
\hline
\end{tabular}

Note: Values are expressed as mean \pm Standard deviation 
Milling yield is one of the most important criteria of rice quality. Milling yield of rough rice is the estimate of the quantity of head rice and total milled rice that can be produced from a unit of rough rice. It is generally expressed as percentage. Thus, the milling quality of rice may be defined as the ability of rice grain to stand milling and polishing without undue breakage so as to yield the greatest amount of total recovery and the highest proportion of head rice to brokens. The greater the amount of chalkiness in the grain, the more it is prone to grain breakage during milling, resulting in lower head rice yield (Khush et al., 1979).

Dipti et al., (2002) reported that quality rice should have head rice out turn of at least 70 percent. Low head rice out turn may be due to chalkiness, varietal characteristics, cultivation practices, harvesting methods and environmental condition (Juliano, 1985).

In conclusion the present study showed Lower head rice percentage was observed in Anjana (JGL-11118) compared to Pradhyumna (JGL-17004).

\section{References}

Dipti, S. S., Hossain, S. T., Bari, M. N and Kabir, K. A. 2002. Physicochemical and Cooking Properties of some fine rice varieties. Pakistan Journal of Nutrition 1 (4): 188-190.

Food and Agricultural organization of the United Nations. FAOSTAT database. 2014. http://fao.org/site/362.

Food and Agricultural Organization of the
United Nations (FAO). 2004. Rice is Life.ftp://ftp.fao.org/docrep/fao/008/y 5682e/y5682e00.pdf

Food Fortification Initiative (FFI). 2014. Rice fortification's impact on nutrition. Atlanta, USA: FFI. http://www.ffinetwork.org/

Jenkins, D. J., Wolever, T. M and Taylor, R. H. 1981. Glycemic index of foods: a physiological basis for carbohydrate exchange. American Journal of Clinical Nutrition. 34: 362-366.

Juliano, B. O., 1985. Criteria and tests for rice grain qualities. In rice chemistry and Technology. AACC. Pp. 443-524.

Khush, G. S., Paule, C. M and Cruz, N. M. 1979 a. Rice grain quality evaluation and improvement at IRRI. In proceedings of workshop on chemical aspects of Rice Grain Quality. IRRI. Los Banos, Philippines. Pp. 22-31.

Rahman, S., Sharma, M. P and Suman, S. 2006. Nutritional and Medicinal Value of some Indigenous Rice Varieties. Indian Journal of Traditional Knowledge. 6: 454-458.

Sahay, K. M., and Singh, K. K. 2005. Unit operations of agricultural processing. Second revised vikas publishing house. Pvt. Ltd. second reprint.273.

Snedecor, G. W., and Cochran, W. G. 1983. Stastical methods, Oxford and IBH publishing company, New Delhi.

Xinghua, L., Lianhuan, P., Yongshan, L., Jiango, W., Chunhai, S and Fusuo, Z. 2007. Effects of plastic film mulching cultivation under non flooded condition on rice quality. Journal of the Science of Food and Agriculture. 87: 334-339.

\section{How to cite this article:}

Anitha, R., K. Manorama, W. Jessi Sunitha and Sreedhar, M. 2017. Milling Quality Characteristics of Selected Newly Released Rice Varieties of Northern Telangana Region, India. Int.J.Curr.Microbiol.App.Sci. $\quad 6(9): \quad 2880-2882 . \quad$ doi: https://doi.org/10.20546/ijcmas.2017.609.354 